\title{
QUÍMICA NA COZINHA: RELATO DE UMA EXPERIÊNCIA DE ENSINO DE QUÍMICA NA EDUCAÇÃO DE JOVENS E ADULTOS
}

\author{
Carolina Toledo Cavalcante \\ Instituto Federal de Santa Catarina - IFSC Câmpus São José (Brasil) \\ ctcavalcante@gmail.com · https://orcid.org/0000-0003-1666-8315 \\ Franciele Drews de Souza \\ Instituto Federal de Santa Catarina - IFSC - Câmpus São José (Brasil) \\ francieledrews@gmail.com · https://orcid.org/0000-0001-5144-8970
}

\begin{abstract}
Resumo. Com o intuito de contribuir com outros estudos e propostas pedagógicas voltadas à Educação de Jovens e Adultos (EJA), neste artigo discorre-se sobre uma experiência vivenciada nessa modalidade de ensino, envolvendo a utilização do referencial metodológico de Projetos Criativos Ecoformadores (PCEs) no ensino de Química. A experiência em questão consiste no desenvolvimento do PCE "Química na Cozinha: Uso da Cozinha como Laboratório", que ocorreu em uma turma do curso de Operador em Computador do Programa Nacional de Integração da Educação Profissional com a Educação Básica na modalidade de Educação de Jovens e Adultos, ofertado pelo Instituto Federal de Santa Catarina - campus São José. Elaborado e realizado ao longo do ano de 2018, o referido projeto fez parte das atividades propostas para os Estágios Supervisionados do curso de Licenciatura em Química da mesma instituição. Desta forma, para além de descrever as etapas de desenvolvimento do projeto, neste artigo, também são apresentados: o portfólio produzido a partir da sistematização dos trabalhos de polinização elaborados pelos estudantes; e os resultados de um questionário aplicado ao final das atividades, a partir do qual se buscou identificar as impressões gerais dos alunos a respeito da proposta desenvolvida. A partir disso, por fim, são feitas algumas considerações sobre a importância da abordagem do cotidiano no Ensino de Química da EJA, bem como sobre a adoção de estratégias metodológicas que levem em consideração os conhecimentos prévios e as especificidades dos sujeitos desta modalidade de ensino, para o desenvolvimento de processos de real aprendizagem e inclusão.
\end{abstract}

Palavras-chave: Educação de Jovens e Adultos, Estágio Supervisionado, Ensino de Química.

\section{CHEMISTRY IN THE KITCHEN: REPORT OF AN EXPERIENCE OF TEACHING CHEMISTRY IN YOUTH AND ADULT EDUCATION}

\begin{abstract}
In order to contribute to other studies and pedagogical proposals focused on the Youth and Adult Education (YAE), in this article there is an appraisal of a lived experience in this modality of teaching, involving the use of the methodological reference framework of Ecoforming Creative Projects (PCEs) in the teaching of Chemistry. The experience concerned is the development of the PCE "Chemistry in the Kitchen: Use of Kitchen as a Laboratory", carried out in a class of Computer Operator course of the National Program of Integration of Professional Training with Basic Education in the modality of Youth and Adult Education, offered by the Instituto Federal de Santa Catarina - Campus São Jose. Prepared and carried out during the year 2018, this project was an integral part of the activities proposed for the Supervised Internships of the course of Degree in Chemistry of the same institution. Thus, in this article, in addition to
\end{abstract}


describing the development stages of the project, the following are also presented: the portfolio produced from the systematization of the pollination works elaborated by the students; and the results of a questionnaire applied at the end of the activities, from which we sought to identify the general impressions of the students regarding the proposal developed. From this, finally, some considerations are made on the importance of addressing everyday Teaching of Chemistry of YAE, as well as on the adoption of methodological strategies that take into account the previous knowledge and the specificities of the subjects of this modality of teaching, for the development of processes of actual learning and inclusion.

Keywords: Youth and Adult Education, Supervised internship, Chemistry Teaching.

\title{
QUÍMICA EN LA COCINA: RELATO DE UNA EXPERIENCIA DE ENSEÑANZA DE LA QUÍMICA EN EDUCACIÓN DE JÓVENES Y ADULTOS
}

\begin{abstract}
Resumen. Para contribuir a otros estudios y propuestas pedagógicas centradas en la Educación de Jóvenes y Adultos (EJA), en este artículo se evalúa una experiencia vivida en esta modalidad de enseñanza, que implica el uso de la referencia metodológica de los Proyectos Creativos Ecoformadores (PCEs) en la enseñanza de la química. La experiencia en cuestión es el desarrollo del PCE "Química en la cocina: Uso de la cocina como laboratorio", realizado en una clase de Operador de Computación del Programa Nacional de Integración de la Educación Profesional con la Educación Básica en la modalidad de Educación de Jóvenes y Adultos, ofrecido por el Instituto Federal de Santa Catarina - Campus São José. Preparado y llevado a cabo durante el año 2018, este proyecto fue parte integral de las actividades propuestas para las pasantías supervisadas de la licenciatura en química de la misma institución. Así, en este artículo, además de describir las etapas de desarrollo del proyecto, se presenta lo siguiente: el portafolio producido a partir de la sistematización de los trabajos de polinización elaborados por los estudiantes; y los resultados de un cuestionario aplicado al final de las actividades, a partir de los cuales buscamos identificar las impresiones generales de los estudiantes con respecto a la propuesta desarrollada. A partir de esto, finalmente, se hacen algunas consideraciones sobre la importancia de abordar el cotidiano de la Enseñanza de La Química de la EJA, así como sobre la adopción de estrategias metodológicas que tengan en cuenta los conocimientos previos y las especificidades de los sujetos de esta modalidad de la docencia, para el desarrollo de procesos de aprendizaje e inclusión reales.
\end{abstract}

Palabras clave: Educación de Jóvenes y Adultos, Pasantía Supervisada, Enseñanza de la Química.

\section{Introdução}

Com o intuito de contribuir com outros estudos e propostas pedagógicas voltadas à melhoria dos processos formativos na Educação de Jovens e Adultos (EJA), neste artigo, discorre-se sobre uma experiência vivenciada nesta modalidade de ensino, envolvendo a utilização do referencial metodológico de Projetos Criativos Ecoformadores (PCEs) (Torre e Zwierewicz, 2009) no ensino de Química. A experiência em questão trata do desenvolvimento do projeto intitulado "Química na Cozinha: Uso da Cozinha como Laboratório", que ocorreu com e em uma turma do curso de Operador em Computador do Programa Nacional de Integração da Educação Profissional com a Educação Básica na modalidade de Educação de Jovens e Adultos (PROEJA), ofertado pelo Instituto Federal de Santa Catarina - campus São José (IFSC-SJ). 
Elaborado e realizado ao longo do ano de 2018, o referido projeto fez parte das atividades propostas para os Estágios Supervisionados do curso de Licenciatura em Química da mesma instituição, no qual a primeira autora deste trabalho é acadêmica e as demais, docentes. Desta forma, para além de descrever as etapas de desenvolvimento do projeto, neste artigo, também são apresentados: o portfólio produzido a partir da sistematização dos trabalhos de polinização elaborados pelos estudantes; e os resultados de um questionário aplicado ao final das atividades, a partir do qual se buscou identificar as impressões gerais dos alunos a respeito da proposta desenvolvida nas aulas de regência em Química. Com isso, para além da contribuição já mencionada, por meio deste relato também se pretende sinalizar algumas considerações para a formação de professores.

Para que se possa melhor compreender o contexto no qual se deu a experiência relatada neste artigo, contudo, considera-se primordial, primeiramente, apresentar alguns aspectos históricos da Educação de Jovens e Adultos (EJA) no Brasil, em geral, e do PROEJA, em particular, bem como uma breve caracterização de quem são os sujeitos da referida modalidade de ensino e de como está organizado o curso do PROEJA ofertado pelo IFSC-SJ, tendo em vista algumas destas características. Além disso, acredita-se ser igualmente relevante apresentar uma explicação sobre como estão organizadas determinadas práticas dos Estágios Supervisionados da Licenciatura em Química do IFSC-SJ, de modo a se esclarecer sua relação com a proposta metodológica dos PCEs, bem como para melhor compreensão do presente Relato de Experiência. É sobre tudo isso que tratam as duas próximas seções deste trabalho.

\section{EJA, PROEJA e IFSC-SJ: uma breve contextualização inicial}

A Educação de Jovens e Adultos é um direito das pessoas e dever do Estado, expressa na Constituição da República Federativa do Brasil de 1988, sendo garantido o “[...] ensino fundamental obrigatório e gratuito, assegurada, inclusive, sua oferta gratuita para todos os que a ele não tiveram acesso na idade própria [...]" (Brasil, art. 208, 1988). Contudo, foi somente em 1996 com a Lei 9394 - Lei de Diretrizes e Bases da Educação Nacional (LDB), que a Educação de Jovens e Adultos passou a se constituir como a conhecemos hoje. Essa lei garantiu o direito à educação também às pessoas excluídas do ensino médio em idade considerada própria.

No que se refere ao público da EJA, quem são, em geral, os sujeitos que procuram a elevação da escolaridade nesta modalidade de ensino? Conforme retratado por diferentes pesquisas realizadas no campo da Educação, e, inclusive, destacado em documentos governamentais oficiais sobre o tema:

A EJA, em síntese, trabalha com sujeitos marginais ao sistema, com atributos sempre acentuados em consequência de alguns fatores adicionais como raça/etnia, cor, gênero, entre outros. Negros, quilombolas, mulheres, indígenas, camponeses, ribeirinhos, pescadores, jovens, idosos, subempregados, desempregados, trabalhadores informais são emblemáticos representantes das múltiplas apartações que a sociedade brasileira, excludente, promove para grande parte da população desfavorecida econômica, social e culturalmente (Brasil, 2007, p. 11).

... são trabalhadores, maduros, com larga experiência profissional ou com expectativa de (re)inserção no mercado de trabalho e com um olhar 
diferenciado sobre as coisas da existência. Para eles, foi a ausência de uma escola ou a evasão da mesma que os dirigiu para retorno nem sempre tardio à busca do direito ao saber (Oliveira, 1999, p. 27).

Tendo em vista essa caracterização, dentre outros aspectos, há pouco mais de uma década foi criado o PROEJA: um programa que busca integrar duas modalidades de educação, a EJA e a Educação Profissional. Instituído e regulamentado pelo Decreto da Presidência da República $n^{\circ}$. 5.840, de 13 de julho de 2006. O PROEJA prevê não somente a complementação dos estudos básicos, mas também possibilita a esses jovens e adultos um aprimoramento profissional, para que possam se inserir de forma mais qualificada no mercado de trabalho brasileiro (Brasil, 2006). De acordo com um de seus documentos-base publicados pelo Ministério da Educação (MEC), esse programa pode ser definido como “... uma política pública estável voltada para a EJA que contemple a elevação da escolaridade com profissionalização no sentido de contribuir para a integração sociolaboral desse grande contingente de cidadãos cerceados do direito de concluir a educação básica e de ter acesso a uma formação profissional de qualidade" (Brasil, 2007, p.11).

Para viabilizar o referido acesso a uma formação profissional de qualidade, o mesmo Decreto $n^{\circ}$ 5.840/2006 atribuiu às instituições federais de Educação Profissional a obrigatoriedade de disponibilização de, no mínimo, $10 \%$ do total de suas vagas de ingresso para cursos e programas regulares do PROEJA.

Desta forma, levando em conta a mencionada atribuição legal e as necessidades formativas dos alunos-trabalhadores que não tiveram acesso ou tiveram que se ausentar da escola na idade regular, a partir de 2008, o Instituto Federal de Santa Catarina (IFSC) passou a ofertar vagas no PROEJA, por meio da abertura de duas categorias de cursos. Uma destas categorias é a de cursos técnicos integrados com o Ensino Médio, com duração entre 2 e 3 anos e meio; e a outra, de cursos de qualificação profissional integrados com o Ensino Fundamental ou com o Ensino Médio, com, no máximo, 2 anos de duração. De acordo com informações publicadas pelo IFSC, atualmente, a oferta destes cursos tem sido feita pela maioria dos 22 campi da instituição, dentre eles, o de São José (IFSC-SJ), que a partir de 2016 passou a ofertar o curso de Formação Inicial em Operador de Computador no referido programa.

Voltado à qualificação profissional na área em questão e à formação básica em nível médio, de acordo com o Projeto Pedagógico do Curso (PPC) em questão, a partir desta integração, almeja-se que os estudantes egressos sejam capazes de: instalar, configurar e operar alguns tipos de sistemas operacionais; atuar na área de sistemas de informação, com atenção às normas e políticas de segurança da informação e de respeito à propriedade intelectual; e exercer sua atividade profissional com base em princípios éticos e de modo sustentável, dentre outras competências relacionadas à formação integral e crítica para o exercício da cidadania (IFSC, 2015).

Para o alcance destas competências, o curso do PROEJA do IFSC-SJ teve sua matriz curricular organizada da seguinte forma: 


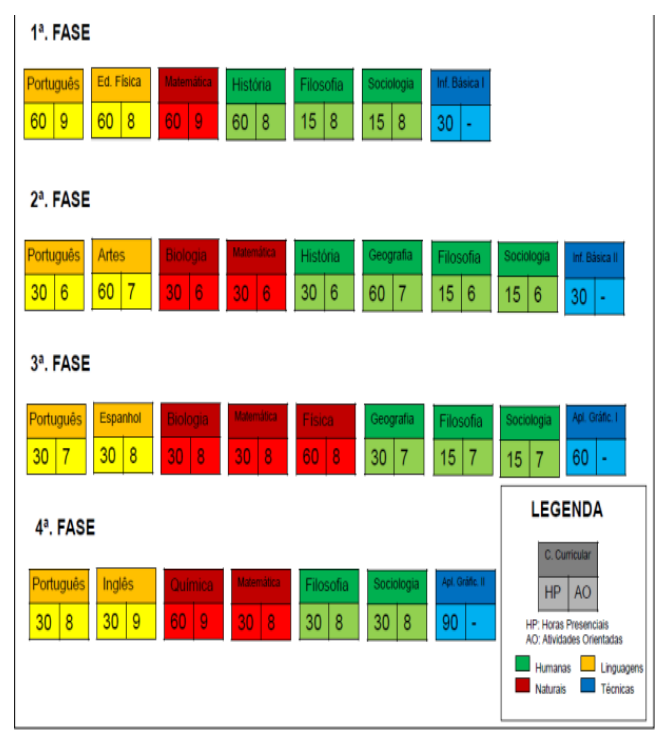

Figura 1. Matriz curricular do curso de PROEJA do IFSC-SJ

Fonte: IFSC (2015, p. 6)

Ainda de acordo com o PPC, no que se refere à formação de nível médio, sua proposta curricular foi assim estruturada "[...] de modo a atender o equilíbrio entre as três grandes áreas presentes nos Parâmetros Curriculares Nacionais (PCN's): Ciências Humanas e suas Tecnologias; Linguagens, Códigos e suas Tecnologias; e Ciências da Natureza, Matemática e suas Tecnologias" (IFSC, 2015, p. 4-5). E é por esta razão, conforme se pode observar na Figura acima, que tal proposta apresenta um componente curricular de Química, na última etapa formativa do curso. Algo que possibilitou à primeira autora deste trabalho realizar seus estágios de observação e de regência em Química com/em uma das turmas, conforme proposta de organização dos Estágios Supervisionados da Licenciatura em Química também ofertada pelo IFSC-SJ, a qual é descrita a seguir.

\section{PCE e portfólio no estágio da Licenciatura em Química do IFSC-SJ}

A partir do olhar de Oliveira (1999) sobre o assunto, entende-se que os jovens e adultos da modalidade de ensino discutida neste trabalho são sujeitos de conhecimento e de aprendizagem, com vivências e especificidades etárias, socioeconômicas e, sobretudo, culturais muito próprias. Como qualquer jovem e adulto, eles trazem “... consigo uma história mais longa (e provavelmente mais complexa) de experiências, conhecimentos acumulados e reflexões sobre o mundo externo, sobre si mesmo e sobre as outras pessoas ..." (Oliveira, 1999, p. 60). Algo que, por si só, já exige que os processos de ensinoaprendizagem sejam pensados a partir de uma perspectiva diferente em relação àqueles envolvendo crianças. No entanto, para além destas características gerais, ainda segundo a referida autora, existe uma especificidade cultural muito relevante que não pode ser ignorada quando se trata do público da EJA: a condição de excluídos da escola regular. Sobre isso salienta Oliveira (1999):

... o aspecto específico dessa ampla questão que se destaca é como a situação de exclusão contribui para delinear a especificidade dos jovens e adultos como sujeitos de aprendizagem. Um primeiro ponto a ser mencionado aqui é 
a adequação da escola para um grupo que não é o 'alvo original' da instituição. Currículos, programas, métodos de ensino foram originalmente concebidos para crianças e adolescentes que percorreriam o caminho da escolaridade de forma regular ... De certa forma, é como se a situação de exclusão da escola regular fosse, em si mesma, potencialmente geradora de fracasso na situação de escolarização tardia (Oliveira, 1999, p. 61-62).

É tendo em vista ponderações como estas que se considera, por conseguinte, tão importante a investigação de metodologias alternativas de ensino na EJA, em geral, e em cursos do PROEJA, em particular, para o desenvolvimento de processos de real aprendizagem e inclusão destes alunos. Neste trabalho, acredita-se que essa relevância se destaca, sobretudo, quando se trata do ensino de Química de nível médio, cujas dificuldades de aprendizagem dos conteúdos não são um problema atual e nem um "privilégio" da EJA, conforme sinalizado por pesquisas na área de Educação em Química ao longo das últimas décadas.

Nesse sentido, uma metodologia que poderia se constituir como uma alternativa inovadora para o ensino na Educação de Jovens e Adultos, considerando as colocações anteriores, seria a dos Projetos Criativos Ecoformadores (PCEs), proposta inicialmente por Torre e Zwierewicz (2009) e complementada por Torre $e$ outros (2015). Na literatura, são descritas mais experiências do uso dos PCEs com crianças e adolescentes (Pukall e outros, 2017; Zwierewicz e outros, 2016; Pereira, Aguiar e Rosa, 2018). Apesar disso, acredita-se que este referencial metodológico também é pertinente para os processos formativos dos sujeitos da EJA, na medida em que se pauta em pressupostos teóricos que buscam superar “... a competição entre os estudantes, a exclusão dos que não se adaptam ao processo de reprodução e a fragmentação dos conhecimentos, distanciando-os da realidade ..." (Zwierewicz e outros, 2016, p. 396).

Atualmente, existe a Rede Internacional de Escolas Criativas, que tem tornado possível, dentre outros aspectos, a difusão do uso dos PCEs em instituições educativas de diferentes níveis de ensino, em diversos locais do Brasil e do mundo (Pujol e outros, 2007). O IFSC-SJ está dentre estas.

Desde 2015, no campus do IFSC de São José, uma adaptação dos PCEs tem sido utilizada por acadêmicos do curso de Licenciatura em Química, no desenvolvimento de suas aulas de regência, durante os Estágios Supervisionados. Conforme sintetizam Aguiar e outros (2017), tendo os PCEs como referencial teórico-metodológico, durante os estágios, os licenciandos constroem projetos de intervenção que:

... possuem o epítome como primeira etapa de seu desenvolvimento, que busca o encantamento dos estudantes para o tema que será discutido, e a etapa final é a polinização, que visa socializar e difundir os resultados alcançados pelos estudantes do campo de estágio. Além dessas etapas, os projetos contam ainda com legitimação teórica e pragmática, perguntas geradoras, objetivo geral e uma sequência didática, que é o itinerário de desenvolvimento do projeto. O itinerário é composto pelo conjunto de atividades, pelos objetivos de aprendizagem, pelas estratégias, intervenções e avaliações planejadas aula por aula para o desenvolvimento da temática proposta para a contextualização do ensino de Ciências/Química (Aguiar e outros, 2017, p. 135 e 136)

Conforme se pode depreender do acima exposto, além da utilização de alguns organizadores conceituais da metodologia dos PCEs, estes projetos de intervenção também se caracterizam por organizar o ensino a partir da contextualização dos conteúdos programáticos definidos pelas escolas-campo de estágio para a disciplina escolar de 
Química. De modo geral, isto tem sido feito por meio da escolha e abordagem de um tema, conforme mencionado por Aguiar e outros (2017). Mas, em alguns outros casos, a contextualização também tem sido realizada por meio da abordagem de situações, contextos e/ou fenômenos do cotidiano, como no projeto relatado neste trabalho, em que se utilizou a "cozinha" como contexto de partida para o ensino dos conteúdos de Química, previstos no PPC do PROEJA do IFSC-SJ.

A contextualização tem sido um recurso muito utilizado por professores de Química para relacionar atividades do dia a dia com conceitos científicos (Wartha e outros, 2013). Machado (2005) já apontava a contextualização como sendo uma forma de inserção do cotidiano no processo de ensino-aprendizagem, de modo a realizar uma significação entre sujeito e objeto. $\mathrm{O}$ uso de uma temática contextualizadora para $\mathrm{o}$ ensino, ou mesmo de situações, contextos e/ou fenômenos do cotidiano - como no caso do projeto relatado neste trabalho - pode favorecer a problematização de assuntos relacionados à vida dos estudantes, ou ainda, um estudo das implicações sociais e ambientais para o desenvolvimento científico.

Para que isso aconteça no ensino de Química, o aluno deve ter elucidado com clareza o conceito de Química e associá-lo com o cotidiano. Conforme Rosa e outros (2005) propõe em seu estudo:

A química do cotidiano, por exemplo, se localiza em outros lugares, que não o laboratório: na cozinha, nos seres vivos, na natureza etc. Os discursos voltados para a valorização da química do cotidiano aprofundam possibilidades que vão além das técnicas laboratoriais químicas, apontam para sistemas complexos, com vida própria, cuja existência e funcionamento podem ser explicados através de conceitos científicos. Nessa perspectiva, é bastante comum a expressão "A química está em tudo", confundindo os iniciantes no que se refere ao significado da palavra química: "Química é coisa ou é conhecimento?" (Rosa e outros, 2005, p. 4).

Portanto, levando em conta o que Rosa et al. (2005) mencionam, não se pode cair nessa confusão e sempre se atentar no momento da aplicação de um ensino contextualizado. O que "está em tudo" é o objeto de estudo da Química: as substâncias e os materiais, sua constituição, transformação e propriedades. E sobre isso a Humanidade tem produzido conhecimento desde seus primórdios.

Ainda sobre as práticas de estágio do curso de Licenciatura em Química do IFSCSJ, Aguiar e outros (2017) explicam que "Em uma etapa posterior, estes projetos dos licenciandos em Química, desenvolvidos nas escolas campo de estágio, são registrados em forma de portfólios, almejando contribuir com o processo de formação dos futuros professores." (Aguiar e outros, 2017, p. 136).

A palavra portfólio deriva da união de duas palavras de origem latina portare + foglio, que significa transportar em folhas (Centra, 1994). Essa organização de conhecimentos teriam as vantagens ilustradas por Scheibel e outros (2009):

... o portfólio é uma metodologia de aprendizagem e avaliação que leva o aluno, à reflexão, à autonomia, à liberdade de expressão e à criatividade [sic]. Acredita-se que o que aqui se propõe poderá contribuir para a realização de uma prática escolar que venha ao encontro das necessidades dos cursos de formação de professores. (Scheibel e outros, 2009, p. 3).

Desta maneira, um portfólio de um processo de ensino, desenvolvido por meio de um PCE, pode servir para sistematização de conhecimentos adquiridos ao longo da 
realização dos estágios, contribuindo para a formação do licenciando numa perspectiva crítico-reflexiva e criativa.

Por fim, vale mencionar que, neste trabalho, acredita-se que a proposta de elaboração e desenvolvimento de projetos de intervenção pautados nos PCEs, bem como de construção de portfólios nos Estágios Supervisionados configuram-se como novas possibilidades de ensino no PROEJA e na formação inicial de professores. Algo que se pretende evidenciar a partir do relato da experiência relativa ao projeto "Química na Cozinha: Uso da Cozinha como Laboratório", conforme apresentado nas três próximas seções.

\section{O projeto "Química na Cozinha”: elaboração e desenvolvimento}

Assim como já mencionado, a experiência sobre a qual se discorre neste texto teve como base as atividades desenvolvidas nas e a partir das regências em Química, ministradas pela primeira autora durante um dos Estágios Supervisionados, para uma turma do curso de PROEJA do IFSC-SJ, no segundo semestre do ano de 2018. Foi nestas regências que se deu o desenvolvimento do projeto "Química na Cozinha: Uso da Cozinha como Laboratório".

Para sua elaboração, contudo, foi fundamental a realização de observações participantes da turma do PROEJA, no semestre anterior ao que a estagiária teve oportunidade de praticar a regência. Os alunos, que à época eram da terceira fase do curso de Operador de Computador do IFSC-SJ, foram observados pela licencianda durante 8 aulas, distribuídas ao longo de 4 semanas, no período de 23/03/2018 à 16/04/2018. Visto o módulo de Química ser aplicado somente em semestres pares, foi possível somente observar as aulas de professores de outros componentes curriculares. Conforme levantamento preliminarmente feito com outros professores do curso de Operador de Computador do IFSC-SJ, muitos elogios já haviam sido mencionados para a turma em questão no quesito interesse e participação nas atividades acadêmicas propostas. Algo que se pôde identificar também a partir das observações.

Nas primeiras observações, os alunos se mostraram relativamente incomodados com a presença de uma pessoa "estranha" a observar suas aulas. Entretanto, já era esperado tal reação, considerando que o olhar é uma forma de comunicação e linguagem; o olhar, mesmo que silencioso, causa um efeito diferente a quem ele é direcionado (Bianchetti, 2002). A estagiária era inicialmente uma pessoa "estranha" que observava as aulas e registrava todas as aulas em diários de campo ${ }^{\mathrm{i}}$. Com a convivência constante e ambientação em sala de aula, logo foi possível perceber o interesse que possuíam pela cozinha e alimentos. Portanto, a observação prévia em sala de aula se mostrou um fator decisivo para escolha da temática.

Além de dados coletados em diários de campo a partir das observações, o projeto de intervenção foi construído levando em consideração a ementa prevista para o componente curricular de Química, do quarto semestre do curso do PROEJA. Para a escolha da proposta de contextualização a partir do contexto da "Química da Cozinha" e seu uso como "Laboratório", além das observações participantes da turma, foi aplicado um questionário de modo que se pudesse identificar e considerar na elaboração do projeto aspectos ou assuntos do interesse dos alunos, bem como seus conhecimentos prévios 
sobre o assunto. Desta forma, almejou-se também que o projeto fosse construído com os estudantes, e não somente para eles.

A partir disso e considerando os pressupostos apresentados na seção anterior, o projeto de regência em Química foi construído, desenvolvendo-se a partir do itinerário planejado em uma Sequência Didática organizada em quatro blocos principais de aulas, conforme se descreve a seguir. Os três primeiros blocos, vale esclarecer, foram desenvolvidos ao longo de três semanas, sendo constituídos por três aulas sequenciais de 55 minutos de duração cada. Já o quarto e último bloco, foi composto por um total de seis aulas de 55 minutos de duração cada, sendo três delas realizadas sequencialmente numa semana e as outras, da mesma forma, noutra.

- $\quad$ Primeiro bloco de aulas - Explanação, através de diálogo e problematização inicial dos conhecimentos prévios dos alunos, sobre o que é a ciência Química e sobre a construção de conhecimentos relativos à constituição, propriedades e transformações dos materiais ao longo da história da humanidade. Apresentação da disciplina e do PCE aos alunos.

- Segundo bloco de aulas - Epítome: Preparação de um pudim na cozinha do campus, utilizando-se uma receita de família da estagiária, durante a qual foram explorados alguns conceitos químicos básicos, como a classificação dos materiais em misturas homogêneas e heterogêneas, a definição de pureza e substâncias, e a compreensão macro e submicroscópica dos diferentes estados físicos dos materiais. O principal objetivo deste momento foi desenvolver a compreensão científica sobre a composição química de materiais utilizados e existentes na cozinha, bem como de alguns fenômenos identificados a partir da preparação do pudim, estabelecendo relações com os conhecimentos de senso comum.

- $\quad$ Terceiro bloco de aulas: Preparação de uma calda para o pudim preparado na semana anterior, e estudo da teoria de atomística e de conceitos de termoquímica a partir desta prática realizada novamente na cozinha do IFSC-SJ. Além disso, durante o preparo da calda, foi discutido o reaproveitamento de partes de frutas que seriam descartadas.

- Quarto bloco de aulas - Polinização de Conhecimentos: Neste bloco houve a finalização das explicações sobre modelos atômicos, a realização de uma síntese dos conceitos estudados ao longo dos outros blocos e a preparação dos trabalhos de polinização, os quais consistem em escolher uma receita, relacionando-a com conceitos científicos sobre a constituição, propriedades e transformações dos materiais. Como método avaliativo, os alunos deveriam escolher uma receita de seu interesse, que utilizavam no seu cotidiano e pesquisar suas possíveis relações com os conceitos científicos aprendidos no desenvolvimento do projeto. Assim, como última parte do desenvolvimento deste bloco de aulas, houve e apresentação das receitas dos alunos com sua devida discussão científica, caracterizando-se tal momento como a polinização dos conhecimentos construídos. Os alunos tiveram liberdade para definir a forma de apresentação de seus trabalhos, estimulando-se a sua criatividade.

Durante todo o processo de desenvolvimento do projeto nas regências, prezou-se por uma concepção de educação estruturada a partir do diálogo, para que os alunos atuassem de maneira interativa no mundo que estão inseridos (Vargas e Pereira, 2013). 
Com a observação e desenvolvimento do primeiro bloco de aulas durante a regência, se confirmou a grande necessidade que os alunos tiveram de entendimento, diálogo e contribuição de ideias. Isso corrobora muito com as ideias freirianas em que, ensinar exige um diálogo aberto para demonstrar segurança e aceitar que a contribuição do aluno é parte fundamental para própria constante formação docente (Freire, 1996; Costa, 1999). Mas também, como Aguiar (2012), mostra que educandos adultos têm a necessidade de discussões reais voltadas à realidade deles e que uma educação infantilizada estimula a evasão escolar na EJA (Aguiar, 2012). Portanto, se comprova que o jovem e o adulto precisam ter clareza da finalidade daquele aprendizado para sua vida, principalmente se forem considerados, conforme proposto por Oliveira (1999), como sujeitos de aprendizagem.

Ao entenderem o objetivo do projeto, os alunos tiveram um envolvimento surpreendente nas aulas. Algumas fotos da aplicação e envolvimento dos alunos no projeto podem ser encontradas na Figura 2. Durante todos os blocos, apresentaram suas ideias para receitas e discutiam entre si sobre as formas de como apresentariam os conceitos químicos. A maior parte dos alunos optou pela apresentação de suas receitas e relações com o ensino de Química em forma de slide. Um aluno preferiu apresentar em forma de cartaz como demonstrado na Figura 3.
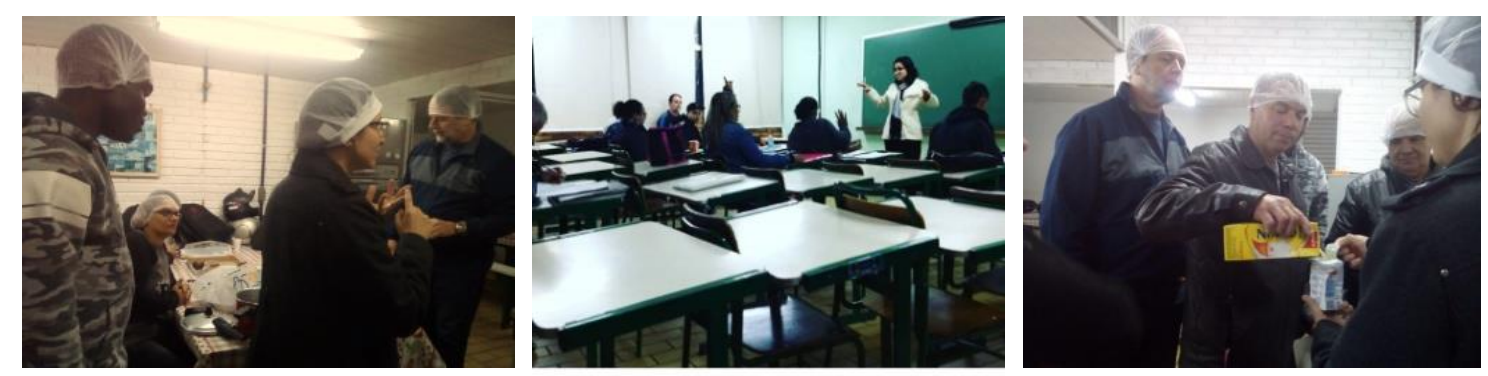

Figura 2. Alunos durante a aplicação do projeto. Fonte: acervo das autoras (2019).
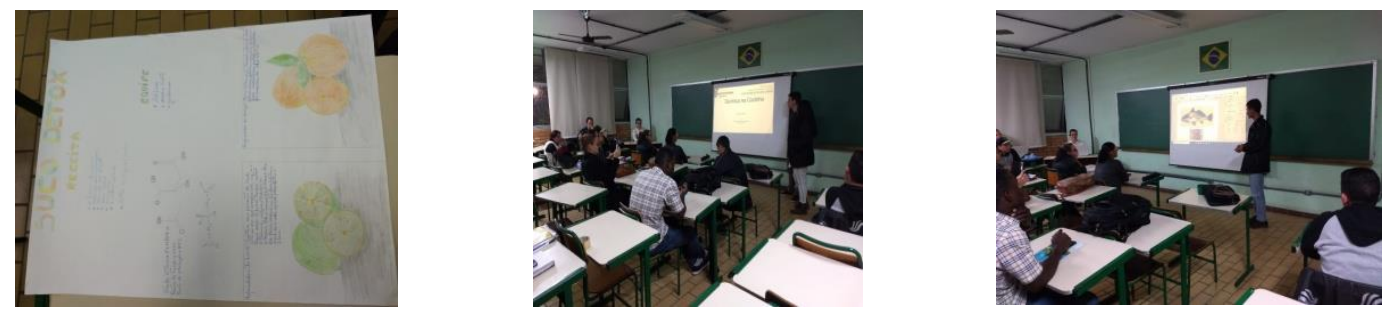

Figura 3. Polinização dos alunos através das apresentações. Fonte: acervo das autoras (2019).

\section{O portfólio do projeto: um caderno de receitas!}

Todos os trabalhos socializados na polinização foram sistematizados em formato de portfólio pela estagiária. O portfólio teve a sua estrutura em forma de livro de receitas. Esse livro de receitas foi dividido nas seguintes seções: Apresentação; Receitas de Aula; Receitas dos Alunos; Fotos das Aulas; Agradecimentos. Na apresentação foram apresentados os sujeitos e o que é contextualização via abordagem de situações, contextos e/ou fenômenos do cotidiano. 
A seção das Receitas de Aula consistiram na visão da estagiária das aulas, a qual, após cada aula, registrava em um diário de campo suas impressões e as atividades desenvolvidas. Dentro do portfólio, portanto, a estagiária optou por resumir e sistematizar as percepções e observações registradas em seus diários de campo, assim o fazendo em forma de receitas. Desta forma foi possível estabelecer a atividade desenvolvendo a criatividade, vinculada a formação de professores (Scheibel, 2009).

A parte intitulada Receitas dos Alunos foi confeccionada com o que eles haviam apresentado na atividade avaliativa, ou seja, na etapa de polinização do projeto. Nela, constam as receitas escolhidas pelos alunos e os conceitos de química que aplicaram para compreensão de fenômenos químicos, bem como da constituição e propriedades químicas dos materiais envolvidos.

Algumas imagens da versão final do portfólio podem ser verificadas na Figura 4.
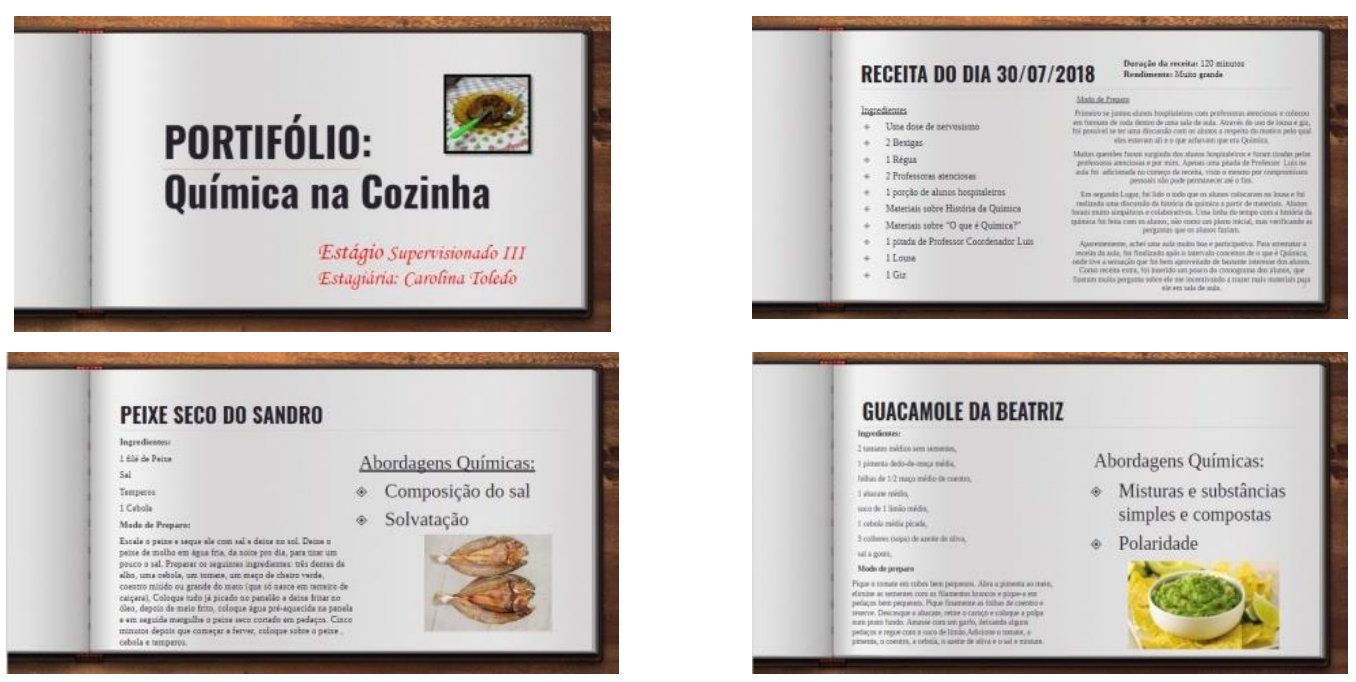

Figura 4. Algumas experiências de aula registradas no portfólio. Fonte: acervo das autoras (2019).

Como verificado na Figura 4, as receitas selecionadas eram relacionadas às próprias vivências dos alunos. Um exemplo foi a receita do aluno Sandro, que tem como atividade profissional, a pesca. Ele mostrou conceitos químicos de solvatação e composição do sal de cozinha através de uma receita que ele realiza semanalmente na sua atividade profissional.

Essa forma de organização do portfólio, o qual mais tarde foi apresentado para a turma do PROEJA, foi fundamental para aprendizagem da estagiária e dos alunos envolvidos. Para os alunos, o portfólio contribuiu para uma visualização geral de todo o projeto desenvolvido e, inclusive, dos trabalhos elaborados e apresentados por eles na polinização. Além disso, tiveram a possibilidade de se responsabilizar pelas escolhas feitas, verificarem sua aprendizagem e assumir autoria por uma seção do livro.

Nesse portfólio, a aprendizagem comum para aluno e estagiária foi a mesma atribuída por Schores (2001) como importante na autoavaliação e avaliação geral do processo e na forma de trazer esse novo olhar crítico sobre todo o trabalho. Além disso, ambos - estagiária e alunos do PROEJA - desenvolveram suas capacidades de síntese. Essa capacidade de síntese foi evidenciada no momento em que os alunos relacionaram conceitos de Química às suas receitas e, no caso da estagiária, no momento da organização do portfólio. 
O significativo interesse dos alunos com os trabalhos da polinização e com o portfólio confeccionado fez com que professores, que ministravam outros componentes curriculares no curso do PROEJA do IFSC-SJ, considerassem a realização de novas atividades a partir da aplicação do projeto, dando sequência a ele de forma interdisciplinar. Desta maneira, os alunos, juntamente com os professores de Inglês, Português e Aplicativos Gráficos II, se engajaram em realizar vídeos das receitas escolhidas, legendando-as em inglês. Estes vídeos foram publicados em um blog criado para divulgação das receitas "químicas" conforme a Figura 5. Como se pode perceber, com isso, a polinização superou as expectativas.

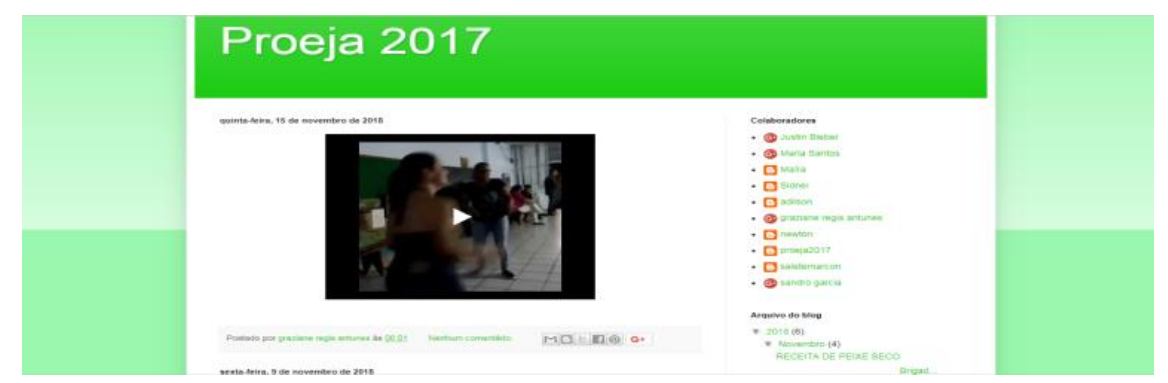

Figura 5. Website criado pelos alunos como polinização continuada.

Fonte: acervo das autoras (2019).

Esse movimento por parte do corpo docente, como consequência do desenvolvimento do projeto de intervenção "Química na Cozinha: Uso da Cozinha como Laboratório", não só contribuiu para sua polinização para além dos muros do campus, mas também alcançou uma abordagem fundamental na formação de professores, que é a da interdisciplinaridade. A interdisciplinaridade é quando duas ou mais disciplinas relacionam seus principais conceitos com intuito de criar dinamismo pedagógico, quando os professores trabalham aliados no ensino de um conteúdo, sem correlacionados saberes (Morin, 2000, Oliveira, 2017).

\section{O projeto no olhar dos alunos da turma do PROEJA}

Para uma avaliação mais completa do projeto de intervenção desenvolvido no estágio de regência, um questionário foi aplicado ao final do processo, através da ferramenta online gratuita Google Formulários. Este instrumento de coleta de dados foi selecionado, considerando que o curso do PROEJA do IFSC-SJ é voltado para a qualificação profissional na área de Operador de Computadores. Além disso, acredita-se que o uso dessa ferramenta livre, em sala de aula, tenha contribuído ainda mais para troca constante de conhecimento entre a estagiária e os estudantes do PROEJA.

Este questionário era composto por perguntas abertas e fechadas, sendo respondido de forma anônima e com o objetivo de avaliar as impressões da turma sobre o desenvolvimento do projeto "Química na Cozinha: Uso da cozinha como laboratório".

Através da primeira pergunta fechada - "O que você acredita ter sido mais interessante para sua aprendizagem, nas aulas e nas atividades desenvolvidas? Por quê?" - já foi possível avaliar as impressões dos alunos sobre a proposta de contextualização escolhida pela estagiária, para o desenvolvimento do projeto nas aulas de Química. Dos 11 alunos que responderam a questão, 6 mencionaram a abordagem dos conteúdos de 
Química a partir de situações vivenciadas na cozinha como sendo o mais interessantes das aulas.

Tomando por base ainda a pergunta mencionada anteriormente, uma resposta em específico de um aluno chamou atenção: "Toda forma de ensino que usa o cotidiano como didática é sempre de muito valor, porque conseguimos associar com o nosso dia a dia". Nesta, é possível identificar como a contextualização do ensino de Química pode ser uma grande aliada para motivar os alunos para a aprendizagem.

Em outras cinco respostas, de diferentes alunos, foram significativas as referências que levaram em conta o contexto dos alunos no processo de ensino-aprendizagem, sendo que todos mencionaram de alguma forma as receitas, as atividades na cozinha e o aprendizado a partir destas.

No questionário ainda existia uma questão que pedia sugestões de experiências futuras da estagiária como professora de Química, e como o aluno avaliava a licencianda. Nessa questão, dos 11 alunos respondentes, todos avaliaram como bom o desempenho dela, e chamaram novamente atenção para a forma de como a estagiária se comunicou utilizando a "linguagem deles", conforme alguns se referiram. Uma das sugestões que mais chamou a atenção foi esta: "Usar sempre esta forma de ensino que leva uma fala mais informal que facilite a comunicação entre alunos e professores”. Portanto, após a aplicação deste questionário verificou-se que, de uma forma geral, o uso da contextualização e de uma linguagem cotidiana entre aluno professor é fundamental para que o aluno do EJA faça a significação daqueles conhecimentos de forma a diminuir a exclusão e competição entre os alunos (Machado, 2005; Zwierewicz, e outros, 2016).

\section{Considerações finais}

Tendo em vista o relato apresentado neste trabalho, acredita-se que a realização do projeto de intervenção "Química na Cozinha: Uso da Cozinha como Laboratório", pautado na metodologia dos PCEs, juntamente com a perspectiva de valorização dos conhecimentos prévios dos alunos, demonstrou resultados significativos para o ensino de Química no contexto da EJA. Além disso, estimulou com que os alunos engajassem professores de outros componentes curriculares a desenvolverem outras atividades relacionadas ao projeto, proporcionando uma experiência de interdisciplinaridade e, por conseguinte, uma polinização para além da comunidade escolar do IFSC-SJ, através da apresentação dos trabalhos elaborados pelos alunos em um blog da turma na internet.

Outras considerações a serem feitas também dizem respeitos à formação da primeira autora como professora de Química. A realização das observações participantes, o desenvolvimento do projeto e a construção do portfólio, além de outros aspectos que perpassam a experiência relatada neste trabalho, ajudaram para que a estagiária trouxesse um novo olhar e significação no seu processo de formação docente. Como futura docente de Química, a estagiária entendeu a importância do uso, mesmo que adaptado, dos Projetos Criativos Ecoformadores como forma de abordar uma situação, contexto e/ou fenômenos do cotidiano, para que a compreensão da importância do aprendizado em Química e para aplicação destes na interpretação da realidade.

Por fim, no que se refere à análise das respostas dos questionários dos estudantes sobre a realização das regências em questão, demonstrou que a aplicação de metodologias alternativas com jovens e adultos fez com que os alunos associassem os conceitos de 
Química com seus cotidianos. Desta forma, acredita-se que propostas e experiências, como a relatada neste trabalho, possam contribuir tanto na formação de professores quanto de jovens e adultos da modalidade de ensino em questão, proporcionando para ambos um aprendizado problematizador, reflexivo e crítico.

\section{Referências}

Aguiar, P. A. (2012). Letramentos de adultos em processo de alfabetização: reflexos da escolarização nas práticas de leitura. Florianópolis: Universidade Federal de Santa Catarina - UFSC.

Aguiar, P. A. e Drews, F. (2017). Ementa Curricular da disciplina de Estágio Supervisionado de Licenciatura em Química do Campus São José, IFSC, São José. IFSC.

Brasil (1988). Congresso Nacional. Constituição Federal da República Federativa do Brasil. 5 de outubro 1988. Brasília: Congresso Nacional.

Brasil (1996). Congresso Nacional. Lei Federal no 9.394. Lei de Diretrizes e Bases da Educação Nacional. 20 de dezembro de 1996. Brasília: Congresso Nacional.

Brasil (2006). Congresso Nacional. Decreto $N^{o} 5.840$ Programa Nacional de Integração da Educação Profissional com a Educação Básica na Modalidade de Educação de Jovens e Adultos - PROEJA. Brasília: Congresso Nacional.

Brasil/MEC (2007). Secretaria de Educação Profissional e Tecnológica Educação Profissional Técnica de Nível Médio Integrada ao Ensino Médio. Documento Base. Brasília: MEC. Recuperado em 19 de maio de 2019, de http://portal.mec.gov.br/setec/arquivos/pdf2/proeja_medio.pdf.

Bianchetti, L. (2002). Um olhar sobre a diferença: as múltiplas maneiras de olhar e ser olhado e suas decorrências. Revista brasileira de educação especial, 8(1), 1-8.

Bonilla, E. e Rodríguez, P. (1997). Más allá de los métodos. La investigación en ciencias sociales. Bogotá: Editorial Norma.

Camargo, A. L. C. (1999). Mudanças na avaliação da aprendizagem escolar na perspectiva da progressão continuada: questões teóricas-práticas. In: M. A. V. Bicudo e C. A. Silva Júnior (Org). Formação do educador: avaliação institucional, ensino e aprendizagem. São Paulo: UNESP.

Centra, J. (1994). The use of the teaching portfolio and student evaluation for summative. Journal of Higher Education, 65(5), 555-570.

Chagas, A. T. R. (2000) O questionário na pesquisa científica. Administração OnLine: Prática, Pesquisa, Ensino, São Paulo, 1(1), 23-48.

Costa, A. O. (2012). De Língua Portuguesa, da Seduc. Formação política e trabalho: uma proposta reflexiva de contextualização na Educação de Jovens e Adultos. Editora Realize.

Oliveira, E. B e Santos, F. N. (2017). Pressupostos e definições em interdisciplinaridade: diálogo com alguns autores. Interdisciplinaridade. Revista do Grupo de Estudos e Pesquisa em Interdisciplinaridade, 11, 73-87. 
Di Pierro, M. C., Joia, O. e Ribeiro, V. M. (2001) Visões da educação de jovens e adultos no Brasil. Cadernos Cedes, 21(5), 58-77.

Freire, P. (1996). Pedagogia da autonomia: saberes necessários à prática educativa. São Paulo: Paz e Terra.

Machado, N. J. (2005). Interdisciplinaridade e contextuação. In: Ministério da Educação, Instituto Nacional de Estudos e Pesquisas Educacionais Anísio Teixeira. Exame Nacional do Ensino Médio (ENEM): fundamentação teórico-metodológica. Brasília: MEC; INEP.

Morin, E. (2000). Os Sete Saberes necessários à Educação do Futuro. $2^{\mathrm{a}}$. ed. São Paulo: Cortez.

Oliveira, M. K. (1999). Jovens e adultos como sujeitos de conhecimento e aprendizagem. Revista Brasileira de Educação, 12, 59-73.

Pereira, G. A., Aguiar, P. A. e Rosa, T. P. (2015). Projetos criativos ecoformadores nos estágios da licenciatura do IFSC campus São José: o olhar dos professores orientadores de estágio. Revista Electrónica de Investigación y Docencia - REID, 19, 87-108.

Pujol, M. A. e Sanz, G. (Coord) (2007). Transdisciplinariedad y Ecoformación. Una nueva mirada sobre la educación. Madrid: Editorial Universitas.

Pukall, J. P., Souza, L. V. e Zwierewicz, M. (2017). Ecoformação na Educação Básica: Uma Experiência Em Formação de Professores. Professare, 6(1), 89-110.

Rosa, M. I. P. e outros (2007). O lugar da Química na escola: movimentos constitutivos da disciplina no cotidiano escolar. Ciência \& Educação, 11(2), p. 253-262, 2005 Sanceverino, A. R. (2016) Mediação pedagógica na educação de jovens e adultos: exigência existencial e política do diálogo como fundamento da prática. Revista Brasileira de Educação 21(65), 455-475.

Scheibel, M. R., Schirlo, A. C. e Foggiatto, R. M. C. (2009) Portfólios: Uma opção metodológica para o ensino de ciências, Anais Encontro Nacional de Pesquisa em Educação em Ciências.

Shores, E. F. e Cathy G. (2001). Manual de Portfólio: um guia passo a passo para professores. Porto Alegre: Artmed.

Vargas, P. G. e Gomes, M. F. C. (2013) Aprendizagem e desenvolvimento de jovens e adultos: novas práticas sociais, novos sentidos. Educação e Pesquisa, 39(2), 449463.

Torre, S., Pujol, M. A., Pasquali, S. e Silva, V. L. S. (2015). Novos Talentos: processos educativos com Projetos Criativos Ecoformadores. Projetos Criativos Ecoformadores - PCEs: Uma via metodológica desde e para o paradigma da complexidade. (pp. 45-58). Blumenau: Nova Letra.

Torre, S. e Zwierewicz, M. (2009). Projetos Criativos Ecoformadores. In: M. Zwierewicz e S. Torre (Coord.) Uma escola para o século XXI: escolas criativas e resiliência na educação (pp. 153-175). Florianópolis: Insular.

Wartha, E. J., Silva, E. L. e Bejarano, N. R. R. (2013) Cotidiano e contextualização no ensino de química. Revista Química nova na escola, 35(2), 84-91. 
Zwierewicz M. e outros (2016). Escolas Criativas: experiências transformadoras potencializadas na interação do Ensino Superior com a Educação Básica. Revista Polyphonía, 27(1), 393-414.

i Diário de campo é uma ferramenta etnográfica que permite sistematizar as experiências em sala de aula tomando nota dos eventos ocorridos para posterior organização e análise dos dados pelo investigador (Bonilla e Rodrigues, 1997).

Data da recepção: $26 / 07 / 2019$

Data da revisão: 22/10/2019

Data do aceite: $23 / 10 / 2019$ 